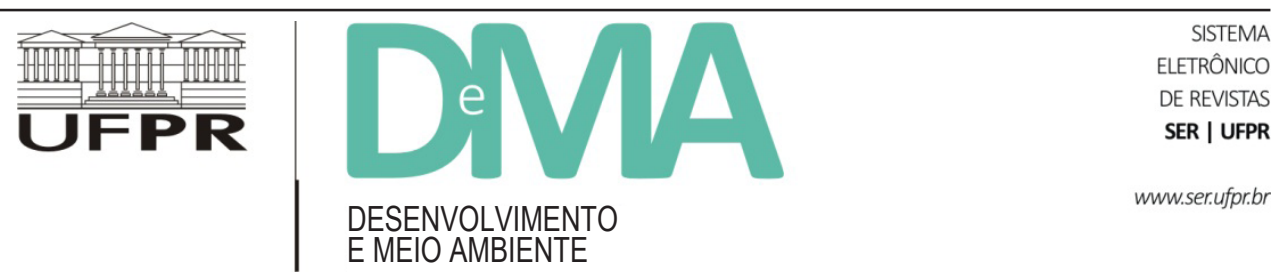

\title{
Pensando as práticas organizacionais no ambiente: as contribuições da perspectiva do habitar
}

\section{Thinking about Organizational Practices in the Environment: Contributions from the Dwelling Perspective}

\author{
Marina Dantas de FIGUEIREDO ${ }^{1 *}$ \\ ${ }^{1}$ Programa de Pós-Graduação em Administração, Universidade de Fortaleza (UNIFOR), Fortaleza, CE, Brasil. \\ *E-mail de contato: marina.dantas@gmail.com
}

Ensaio recebido em 5 de maio de 2014, versão final aceita em 19 de fevereiro de 2015.

RESUMO: Este ensaio objetiva esboçar uma forma vivencial de compreender a organização a partir de uma perspectiva incorporada, que privilegie a análise das práticas organizacionais situadas no ambiente. Tomamos a perspectiva do habitar a fim de enriquecer a compreensão do mundo da vida, no qual a percepção ocorre, para esclarecer como o conhecimento emerge das práticas situadas do viver. Este artigo propõe uma abordagem que descreve as práticas do viver com base no entrelaçamento com o mundo da vida, como um processo corporificado (embodied) e situado no ambiente. O trabalho apresenta novas possibilidades de pesquisa sobre a relação entre pessoas e organizações, uma vez que a perspectiva do habitar possibilita a compreensão de que a organização não é apenas um espaço habitado, mas é um espaço de vida. A contribuição se dirige a preencher duas lacunas identificadas nos estudos sobre as práticas nos Estudos Organizacionais: (1) o esforço de resgatar o potencial crítico das práticas em relação aos conceitos positivistas e racionalistas impostos aos estudos organizacionais, e (2) a necessidade de promover uma articulação mais clara do entrelaçamento com o mundo da vida, que é crucial para a análise da prática situada no ambiente.

Palavras-chave: ambiente; práticas; perspectiva do habitar; mundo da vida; entrelaçamento.

ABSTRACT: The purpose of this essay is to outline an experiential way of understanding the organization, from a embodied perspective, that privileges the analyses of organizational practices situated in the environment. We take the dwelling perspective in order to enrich the comprehension of the life-world where the perception takes place and to clarify how knowledge emerges from situated living practices. This paper proposes an approach that describes living practices based on the entwinement with the life-world, such as an embodied process situated in the environment. The paper presents new possibilities of research about the relation between individuals and organizations, as the dwelling perspective enables the comprehension that the organization is not only inhabited, but is a living space. The goal is to fill gaps identified in the two studies on practices in Organizational Studies: (1) the effort to rescue the critical potential of practices in relation to positivist and rationalist concepts 
imposed on organizational studies and (2) the need to promote clearer articulation about the entwinement with life-world, considering that this idea is crucial for the analysis of practice rooted in the environment.

Keywords: environment; practices; dwelling perspective; life-world; entwinement.

\section{Introdução}

Embora estudos sobre as práticas tenham se tornado cada vez mais comuns no âmbito dos Estudos Organizacionais (EOs), alguns autores identificam a necessidade de se examinar mais detalhadamente o que constitui a prática, para que seja possível aprofundar e tornar mais relevantes as contribuições dessa abordagem (Reckwitz, 2001; Gherardi, 2009a; Sandberg \& Dall'Alba, 2009; Geiger, 2009). Um passo importante nesse sentido, conforme propõem Corradi et al. (2010), é distinguir entre a pluralidade de conceituações reunidas sob o rótulo da prática, as tradições filosóficas e sociológicas que fundamentam diferentes entendimentos sobre a questão. Em uma análise similar, Reckwitz (2001) conclui, após a revisão das teorias sobre práticas nas Ciências Sociais, que os estudos sobre as práticas são fragmentados e carecem de maior sistematização a fim de fornecerem alternativas às teorias sociais prevalentes.

As práticas emergem no panorama dos estudos gerenciais e organizacionais na última década, anunciando a virada para uma abordagem crítica nesse campo (Gherardi, 2009a). A análise tradicional do fenômeno organizacional, exemplificada pelos escritos de Weber (2004) sobre a burocracia, conceitua a organização como um aparato ou instrumento desenvolvido para o alcance de determinada meta. Para a visão gerencialista predominante na Administração, tal meta seria a realização da produção com o objetivo de geração de excedentes. Havia, portanto, ênfase sobre a racionalidade da organização, infundida pela intencionalidade dos agentes, da qual derivaria o significado das ações. A partir das teorias da prática, o significado das ações passa a ser entendido como produto de certas condutas que não necessariamente têm um fundamento racional. Ao invés de privilegiar a racionalidade como fundamento para a existência e o funcionamento das organizações, essa abordagem abre possibilidades para que as organizações sejam entendidas sob um ponto de vista ecológico, no qual a agência é distribuída entre as pessoas e o arranjo material no qual as organizações estão inseridas.

Para Sandberg \& Dall'Alba (2009), um desafio a mais para os pesquisadores identificados com as teorias da prática nos EOs é que as abordagens sobre a prática comumente recorrem a uma combinação de perspectivas, como a fenomenologia, o marxismo, o pragmatismo e o construtivismo social. A maioria dessas abordagens, segundo os mesmos autores, é inspirada por aquilo que pode ser chamado de uma perspectiva de mundo da vida, que explica como a prática está ligada a um interesse no cotidiano, no espaço habitado e nas dinâmicas mais usuais e intrínsecas à reprodução das organizações, da cultura e da própria existência humana. Mesmo assim, os autores ponderam que os teóricos da prática no âmbito dos EOs não chegam a adotar essa perspectiva de forma consistente. Embora muitas abordagens baseadas em prática tenham sido inspiradas por uma perspectiva de mundo da vida ou usado alguns de seus conceitos, não se observa, necessariamente, a adoção dessa vertente de forma consolidada ao longo das pesquisas, análise de dados e representação destes nos textos acadêmicos.

O presente artigo objetiva esboçar uma forma vivencial de compreender a organização a partir de uma perspectiva incorporada (Ingold, 2000; Csordas, 2008) partindo da necessidade de esclarecer os limites entre as abordagens sobre as práticas nos EOs, de oferecer alternativas às análises organizacionais hegemônicas neste mesmo campo e de resgatar a perspectiva do mundo da vida que se manifesta vagamente em muitos estudos sobre a temática das práticas. Tendo por pano de fundo esses aspectos, depreende-se que a performance das práticas organizacionais pode ser observada e compreendida mais de perto, trazendo-se para o foco das discussões a maneira como a prática é constituída e se mantém por meio de nossa relação corporal e incorporada com outras pessoas, com as coisas e com o mundo.

A perspectiva do habitar (dweling perspective) tal como proposta por Ingold (2000) é carreada para o campo dos EOs para fazer avançar o entendimento 
das práticas em relação ao mundo da vida proposto por Sandberg \& Dall'Alba (2009) de modo a se resgatar e aprofundar o potencial crítico dos estudos sobre as práticas de autores dedicados à temática nas últimas três décadas (Gherardi, 2009a; Geiger, 2009; Corradi et al., 2010), bem como busca ser uma proposta inovadora ao propugnar uma visão axiológica de cunho ecológico.

O texto está organizado da seguinte maneira: primeiro, buscamos organizar o conjunto de estudos sobre as práticas de acordo com as diferentes perspectivas filosóficas e epistemológicas às quais os estudiosos das práticas nos EOs mais comumente se filiam; em seguida, exploramos a necessidade de novas abordagens sobre as práticas, com ênfase à crítica ao trabalho de Sandberg \& Dall'Alba e ao entendimento de mundo da vida enunciado por esses autores; a seguir, aprodundamos o entendimento de mundo da vida a partir da fenomenologia, para chegarmos ao paradigma do embodiment como alternativa emergente nos estudos das práticas. Ao fim do texto, revisamos a proposta inicial do artigo e apresentamos nossas considerações e contribuições às teorias da prática no campo dos EOs.

\section{Teorias da prática}

Tomando por parâmetro a distinção sociológica fundamental entre subjetivismo e objetivismo (Bourdieu, 1996), que também pode ser lida na dualidade cultura e estrutura (Ortner, 1984), Gherardi (2009b) propõe a sistematização dos estudos baseados na prática no âmbito dos EOs em torno de dois grandes grupos, diferenciados em razão dos posicionamentos epistemológicos que levarão os pesquisadores reunidos ao redor de cada um deles a assumirem leituras das práticas "a partir de fora" (from outside) ou "a partir de dentro" (from inside).

Quando as práticas são lidas "a partir de fora", a investigação se concentra na regularidade das ações, no padrão que organiza as atividades e em uma compreensão compartilhada capaz de assegurar que os praticantes estejam aptos a reproduzi-las através do tempo. A recursividade é o que permite identificar a prática (Giddens, 1984), ainda que a repetição de dada ação no transcurso do tempo não seja suficiente para caracterizá-la. Isso porque, como assinala Gherardi (2009a, p. 536), “as práticas não são apenas padrões recorrentes de ação (no nível da produção), mas também padrões recorrentes de ação socialmente sustentada (no nível da produção e da reprodução)". Em outras palavras, a visão da prática "a partir de fora" não se refere somente àquilo que as pessoas fazem cotidianamente, mas sim àquilo que as pessoas fazem cotidianamente em relação ao contexto social, histórico e estrutural em que as ações ocorrem.

Para Geiger (2009, p. 132), ainda que essa leitura abrigue uma variedade de interesses e tradições de pesquisa, os estudiosos reunidos ao seu redor convergem para o entendimento da prática como um "conceito epistêmico-normativo". As práticas referem-se às construções sociais surgidas no transcurso do tempo, que se mantêm, se renovam e se reúnem em sistemas de práticas (Giddens, 1984). Configuram-se, então, como meios para a institucionalização do que pode ou não ser dito e aceito no seio de um grupo, impondo ordem ao mundo social (Bourdieu, 2002). A leitura das práticas “a partir de fora”, segundo Gherardi (2009b), é uma posição epistemológica que liga a análise das práticas com a análise das ações enquanto rotinas e que corresponde a uma tradição de pesquisa preocupada com a dinâmica e com a recursividade das ações organizacionais (Feldman, 2000; Feldman \& Pentland, 2003; Cohen, 2007).

Quando as práticas são lidas "a partir de dentro", as análises recaem sobre o ponto de vista dos seus praticantes, sobre sua temporalidade, o seu processo e sobre as negociações necessárias para que a ação aconteça. Assim, "vista 'a partir do interior', a prática é uma ação de conhecimento coletivo que forja relações e conexões entre todos os recursos disponíveis e todas as limitações presentes" (Gherardi, 2009b, p. 118). Conforme Geiger (2009, p. 132), os estudos sob essa orientação tomam a prática como perspectiva processual e frequentemente enfocam a análise de microatividades do cotidiano enquanto ações estratégicas. Nesse sentido, pode-se tomar as práticas em uma dimensão micropolítica que se revela capaz tanto de reproduzir quanto de subverter a realidade social (Certeau, 2002; Foucault, 2009). Entende-se também que as práticas são resultado de arranjos materiais que envolvem pessoas, artefatos, organismos e coisas unidos por meio de interconexões em rede (Schatzki, 2006; Latour, 2007). Assim, conforme Gherardi (2009b), a leitura das práticas “a partir de den- 
tro" constitui uma epistemologia de pós-humanista, que se destina a descentrar o sujeito humano (Knorr-Cetina, 1997) ou a reconfigurar a agência como uma capacidade que se realiza por meio da associação de humanos e não humanos (Latour, 2007). A partir do entendimento de que as organizações acontecem enquanto redes tecidas nas práticas que ligam as pessoas e a materialidade das organizações (Schatzki, 2006), o social é uma dinâmica na qual diversos elementos agem, transformam-se e transformam a realidade.

O entendimento de como práticas e ações estão entrelaçadas coloca essas duas grandes correntes das teorias da prática diante de questões tais como: a) a intencionalidade dos agentes sociais (Bourdieu, 1996); b) das razões que motivam as práticas (Sahlins, 2003); c) da finalidade da ação prática (Schatzki, 2006); e d) do próprio conceito de agência (Latour, 2007). De acordo com Gherardi (2009b), as duas vertentes teóricas buscam localizar a fonte de padrões significativos de ações na forma como as condutas são promulgadas, realizadas ou produzidas. Enquanto as teorias de ação começam a partir de indivíduos e de sua intencionalidade para perseguir cursos de ação conforme relações objetivas (econômicas ou linguísticas), as teorias da prática, veem as ações como sendo realizadas por meio de uma rede de conexões que se estabelecem em um mundo vivido e habitado. As duas se colocam contrárias à dualidade agência/estrutura, assim como às várias outras dualidades estabelecidas pelas teorias sociais modernas, como sujeito/objeto e mente/corpo (Reckwitz, 2001). Mas é importante assinalar que a maneira como essas duas correntes de teorias da prática lidam com o princípio de produção das organizações é diversa, principalmente no que diz respeito à inter-relação entre práticas e estruturas (para a leitura das práticas "a partir de fora") ou arranjos (para a leitura das práticas "a partir de dentro").

Para os estudiosos que enfatizam a leitura "a partir de fora", as práticas desenvolvem-se em contextos estruturados que colaboram para que "perpetuem-se a si mesmas" (Schatzki, 1997) através do tempo. Eles asseguram para si o direito a reduzir o conhecimento social às estruturas objetivas, mas na condição de não perderem de vista que a verdade das experiências reside, contudo, nas estruturas que as determinam (Bourdieu, 2002). Este entendimento está claro, por exemplo, na no- ção de habitus como "estrutura estruturada e estruturante que engaja, nas práticas e nas ideias, esquemas práticos de construção oriundos da incorporação de estruturas sociais oriundas, elas próprias, do trabalho histórico de gerações" (Bourdieu, 2002, p. 158). A inclusão do corpo (embodiment) nas reflexões sobre a prática é a resposta dessa corrente das teorias da prática ao estruturalismo e ao subjetivismo (Schatzki, 2001), ou a busca por uma posição intermediária entre os modos de conhecimento teórico formulados pelo objetivismo ou pela fenomenologia (Bourdieu, 2002). Pensar sobre o corpo a partir da construção de estruturas objetivas põe em questão os mecanismos por meio dos quais estruturas e práticas são indissociáveis. A análise da relação entre o agente e a realidade é balizada pelo fato de que as estruturas do mundo social são incorporadas por meio da socialização. O corpo humano se oferece, portanto, como ponto de conexão entre o individual e o social; entre a razão de agentes sociais interessados na prática como jogo social e a consciência transcendental da prática embebida na ordem simbólica da cultura (Sahlins, 2003).

Para as teorias que adotam a leitura "a partir de dentro", há um modelo ecológico no qual a agência é distribuída entre os seres humanos e não humanos e em que a relação entre o mundo social e a materialidade pode ser submetida à investigação (Gherardi, 2009b). O espaço social no qual se desdobra a vida é composto por uma malha de práticas humanas e arranjos materiais em estados de mobilização que resultam na formação de coletivos (Latour, 2007). O social é a arena onde os fenômenos ocorrem (Schatzki, 2006). Para os teóricos alinhados a esse grupo, as tensões entre os níveis de análise micro e macro são colapsadas porque "mesmo uma rede ampla continua a ser local" (Latour, 2007, p. 114). As categorias do universal e do circunstancial se misturam, por exemplo, no conceito de cotidiano de Certeau (2002), que abriga a possibilidade de as práticas assinalarem mais do que um conjunto de ações instituídas e se conformarem por meio de apropriações e articulações das pessoas em redes de relações. O colapso das dimensões micro e macro anuncia que o sentido das ações humanas é produzido no contexto onde as práticas se desenvolvem e que tais práticas estão sujeitas a toda sorte de subversões. Sob o ponto de vista desse grande eixo teórico, o sentido não surge da repetição das práticas 
através do tempo, de suas inscrições nos corpos e na cultura (Giddens, 1984); tampouco existem sistemas de disposições duradouras que exprimam predisposições, tendências, propensões ou inclinações para as práticas (Bourdieu, 2002). O interesse no jogo social está inscrito "sobre um processo, sobre um movimento, uma passagem, literalmente um passe, no sentido que esta palavra tem nos jogos de bola" (Latour, 2007, p. 127).

\section{A necessidade de novas abordagens sobre as práticas}

Tencionando as vertentes que acabamos de descrever, Sandberg \& Dall'Alba (2009) assinalam que uma nova virada para a prática nos EOs deve explorar, de forma crítica, uma ontologia do mundo-da-vida (life-world) como um meio de reexaminar e reconceituar a prática. Os autores apresentam a perspectiva do mundo-da-vida (life-world perspective) para destacar a necessidade de se investigar o entrelaçamento (entwinement) fenomenológico das pessoas com o mundo. Para fazer avançar esse entendimento, os autores oferecem três caminhos para as atuais abordagens da prática nos EOs: “(1) articular a forma como o entrelaçamento da vida no mundo é crucial para a análise das práticas; (2) elaborar e especificar como os aspectos centrais da prática estão inter-relacionados, e (3) oferecer um vocabulário elaborado e distinto para conceituar a prática como entrelaçamento" (Sandberg \& Dall'Alba, 2009, p. 1351). O entrelaçamento, que se coloca como questão central para este conceito, exprime a noção de que pessoa e mundo estão intrinsecamente relacionados na experiência vivida. Desse modo, Sandberg \& Dall'Alba (2009) delineiam alguns conceitos-chave de uma perspectiva do mundo-da-vida para a análise das práticas, quais sejam: entrelaçamento com o mundo, modos de ser, corpo vivo, ser com os outros (being with others) $e$ equipamentos.

A noção de entrelaçamento com o mundo determina que os aspectos da prática como atividades, conhecimento, pessoas e equipamentos estão interligados e tomam o seu significado de mundo de práticas. $\mathrm{O}$ conceito de modos de ser destaca as formas específicas por meio das quais chegamos a compreender a nós mesmos como praticantes no desempenho das atividades que realizamos. A noção do corpo vivo ressalta a maneira como determinadas atividades, conhecimento, equipamentos e relações com os outros, pertencentes a práticas específicas, são integrados e incorporados enquanto saber-fazer por parte dos praticantes. O conceito de ser com os outros enfoca a prática como fato social e historicamente constituído que resulta em formas de organização compartilhadas entre as pessoas por meio da socialização, da educação e do trabalho. Finalmente, o conceito de equipamento destaca como ferramentas e objetos de qualquer tipo contribuem para a constituição de práticas, tanto no sentido de sua utilidade à consecução de etapas específicas das práticas quanto na maneira como o desempenho destas mesmas etapas molda as práticas em si. Sandberg \& Dall'Alba (2009) se preocupam, ainda, em comparar os conceitos-chave da perspectiva do mundo-da-vida com as características comuns às abordagens da prática, conforme expresso na Tabela 1 .

TABELA 1 - Conceitos do mundo-da-vida que dizem respeito às características das abordagens da prática.

\begin{tabular}{ll}
\hline Conceito do mundo-da-vida & $\begin{array}{l}\text { Aspecto das abordagens da } \\
\text { prática }\end{array}$ \\
\hline $\begin{array}{l}\text { Entrelaçamento com os } \\
\text { mundos da prática }\end{array}$ & Não dualismo \\
Modos de ser & Agência humana \\
Corpo vivo & $\begin{array}{l}\text { Embodiment } \\
\text { Ser com os outros }\end{array}$ \\
Equipamentos e extensões do & Inclusãca como social \\
corpo & \\
\hline
\end{tabular}

FONTE: Sandberg \& Dall'Alba (2009).

O caráter relacional da prática é central tanto para a perspectiva do mundo-da-vida de Sandberg \& Dall'Alba (2009) como para as abordagens prevalentes sobre as práticas. Embora esta unidade possa ser percebida nas teorias, Schatzki (1997) chama atenção para as divergências quanto à compreensão da qualidade dessa relação no interior das diferentes vertentes e para a maneira como práticas e ações estão ligadas; ou, mais precisamente, para o modo como "práticas e ações estão entrelaçadas" (Schatzki, 1997, p. 284). Enquanto a ontologia 
tradicional assume o princípio da desconexão - estamos essencialmente separados do mundo, mas nos ligamos a ele à medida que o viver no mundo requer o desempenho de atividades -, a ontologia do mundo-da-vida considera o entrelaçamento com os outros e com as coisas como a nossa principal forma de ser, no sentido de que as identidades sociais que nos definem não podem existir para além do contexto das práticas a que estão relacionadas. "Em outras palavras", segundo Sandberg \& Dall'Alba (2009, p. 1356), “o engajamento nas ações pressupõe nosso entrelaçamento com o mundo"; entrelaçamento este que possibilita essas ações, quando não é justamente a causa das mesmas.

Outras abordagens da prática partem da perspectiva do mundo-da-vida concebendo que as atividades das pessoas são orientadas e dirigidas por um sentido de intencionalidade e agência que tem relação com os de modos de ser que "dão sentido ao que nós fazemos e ao que nós somos" (Sandberg \& Dall'Alba, 2009, p. 1356). A diferença é que a perspectiva do mundo-da-vida se apropria do conceito de intencionalidade incorporada comum aos teóricos culturalistas da prática e considera que os modos de ser constituem o nexo pessoal-social que liga a pessoa ao contexto das práticas. Sandberg \& Dall'Alba (2009) destacam o habitus de Bourdieu e a "consciência prática" de Giddens, assinalando, todavia, que há diferenças importantes entre esses dois conceitos. Para a perspectiva do mundo-da-vida, a proposta inclina-se para a noção de que "a incorporação ou promulgação corporal de práticas sociais podem ser exploradas através da noção do corpo vivo de Merleau-Ponty, que tem influência tanto sobre o conceito de Bourdieu quando do de Giddens" (Sandberg \& Dall'Alba, 2009, p. 1357). Ao ser o meio que possibilita o acesso ao mundo, o corpo vivo está entrelaçado com o mundo social e material, através de várias práticas, que por sua vez ensejam modos particulares de organização.

A proposta apresentada por Sandberg \& Dall'Alba (2009) é pertinente sob muitos aspectos, mas deixa lacunas a serem preenchidas pelos pesquisadores engajados no movimento que os autores chamam de "novo retorno para as práticas" (returning to practice a new), a partir de uma abordagem fenomenológica. Sua principal contribuição é endossar a premência pelo resgate do corpo para o estudo das práticas no contexto organizacional, en- fatizando indiretamente a pertinência de outros trabalhos que abordaram anteriormente a questão da corporeidade a partir de uma perspectiva fenomenológica no campo dos EOs (Strati, 2007; Hancock, 2008). Todavia, cabe ressaltar que a intenção de Sandberg \& Dall'Alba (2009) de elaborar uma forma integrada da conceptualização prática em torno dos conceitos de entrelaçamento com o mundo, modos de ser, corpo vivo, ser com os outros e equipamentos, é realizada de forma incipiente. Eles ressaltam que esses conceitos precisam estar combinados para destacar a compreensão da prática a partir da perspectiva do mundo-da-vida, mas não descrevem a maneira como isso acontece. Parece-lhes suficiente propor que os conceitos estão integrados e ancorar esse entendimento na ideia de que o mundo-da-vida é o contexto de relações onde as pessoas, as práticas e as coisas estão entrelaçadas. O objetivo dos autores é esclarecer como o entrelaçamento com o mundo-da-vida constitui as práticas, muito embora nem a natureza desse entrelaçamento, nem as características do mundo-da-vida sejam exploradas.

Compreendendo as limitações do referido estudo e a carência de outros trabalhos nos EOs que articulem o entendimento do contexto das práticas a partir de uma perspectiva fenomenológica, propomos que seja introduzido neste campo o conceito de habitar, pertinente à perspectiva do habitar (dwelling perspective), desenvolvida por Ingold (2000) no âmbito da Antropologia. Para Ingold, o que se costuma chamar de social é, na verdade, um subconjunto de relações ecológicas em que humanos existem como organismos-pessoa em um mundo repleto de outros seres. Habitar é o processo de engajamento ativo com o ambiente que nos rodeia; é a fusão de corpo e mente, organismo biológico e pessoa culturalmente situada no contexto das práticas que constituem o viver. O contexto das práticas é o sistema onde se vive, formado pelo conjunto de elementos que interagem em uma estrutura específica, formando-a ao mesmo tempo em que são por ela formados.

A partir da noção de habitar, podemos depreender que o entrelaçamento está condicionado à experiência situada das práticas e, mais ainda, aos modos de percepção culturalmente forjados que viabilizam certas formas de estar no mundo. Nessa condição, a experiência não é mediadora entre as coisas dispostas no ambiente e 
as representações contidas na mente. A experiência é intrínseca ao engajamento sensorial que caracteriza a percepção e a consciência da própria pessoa ao movimento dos elementos do ambiente, escolhidos como focos de atenção segundo aspectos culturais incorporados (Ingold, 2000).

Como é propósito deste artigo esboçar uma forma de compreender as práticas organizacionais que venha a suprir a lacuna deixada por um entendimento descontextualizado do entrelaçamento com o mundo-da-vida (Sandberg \& Dall'Alba, 2009), a próxima seção é dedicada à revisão das teorias sobre cultura, percepção e conhecimento para compreender como esse entrelaçamento é produto do trabalho dos sentidos do corpo culturalmente situado (embodiment) sobre o contexto, ou a contextura do ambiente formado por circunstâncias sociais, econômicas e ecológicas.

\section{Cultura, percepção e conhecimento}

Na perspectiva fenomenológica - uma das vertentes para o estudo das práticas -, a subjetividade emerge da existência corporal imediata com o mundo, que é culturalmente anterior. A existência pré-reflexiva não é de modo algum pré-cultural, tal que a percepção, embora coincida com a experiência primeva do mundo, requer um contexto de significação. A apreensão dos sentidos que advêm de uma "nova intenção significativa" é uma descoberta peculiar a cada sujeito e se caracteriza, propriamente, como uma redescoberta porque ganha os contornos de significações já disponíveis, resultantes de atos de expressão anteriores. O fato curioso é que, nas palavras de Merleau-Ponty (2005, p. 249), "as significações disponíveis entrelaçam-se repentinamente segundo uma lei desconhecida", que traz à existência um novo ser cultural capaz de experimentar o mundo como nenhum outro. Quando nossa aquisição cultural se mobiliza a serviço dessa estranha lei, o significar se abre como uma potência indefinida que permite aos sujeitos transcenderem "em direção a um comportamento novo, ou em direção ao outro, ou em direção ao seu próprio pensamento, através de seu corpo e de sua fala" (Merleau-Ponty, 2005, p. 263).
Esse pensamento ocupa o limite entre natureza e cultura pois, de acordo com Merleau-Ponty (2005), mesmo quando estamos absortos na experiência do corpo e na solidão das sensações, não chegamos a suprimir as referências da vida no mundo. Ao mesmo tempo que jamais chegamos a nos tornar inteiramente uma coisa no mundo, a existência corporal nunca repousa em si mesma e está sempre sujeita às influências de estímulos sobre os sentidos. Considerando as dimensões físicas do ambiente e a biologia do corpo humano, Merleau-Ponty (2005, p. 229) propõe que o sujeito é a manifestação inacabada de um dado ser em situação. Nas suas palavras: "é dessa maneira que o corpo exprime a existência total, não que ele seja seu acompanhamento exterior, mas porque a existência se realiza nele" (Merleau-Ponty, 2005).

A experiência do ser-no-mundo resgata o contato direto com o ambiente, que é construído por meio dos sentidos antes de qualquer exercício de compreensão socialmente estruturado. Como propõe Merleau-Ponty (2005, p. vii), “o mundo está 'sempre lá' antes que a reflexão se inicie”, e a operação lógica de depreender o conhecimento começa na experiência não reflexiva, derivada da percepção. Do ponto de vista da fenomenologia, o mundo emerge no processo mesmo de emergir da pessoa, por meio da atividade engajada com o ambiente. O tornar-se ser é parte do processo de tornar-se ser-no-mundo e, para Merleau-Ponty, esta forma de percepção deve estar contida numa presença corporificada (embodied). O corpo é "uma coisa entre outras coisas" (Merleau-Ponty, 2005, p.3); mas como pode perceber a si mesmo e as outras coisas, o corpo torna-se capaz de estabelecer relações de compreensão com o mundo. A subjetividade surge da experiência da objetividade, de si e do entorno: justamente porque estamos imersos no mundo, podemos imaginar a nós mesmos existindo além do mundo.

Para Bourdieu, a sociedade prevê formas de inculcação dos significados da cultura que, sob as aparências da espontaneidade, constituem um sem-número de exercícios estruturais tendentes a transmitir certas formas de experiência. Tem-se que "a relação com o próprio corpo é sempre mediatizada pelo mito" (Bourdieu, 2002, p. 188), tal que as experiências corporais mais fundamentais são qualificadas e modificadas pela inserção do indivíduo na sociedade. A experiência do corpo no espaço acontece 
em "terrenos universalmente impostos"; observa-se então que a sociedade oferece ao indivíduo, enquanto corporeidade, "esquemas de referência em articulação com o qual o mundo pode ordenar-se, ao mesmo tempo em que as estruturas elementares da experiência corporal coincidem com os princípios de estruturação do espaço objetivo" (Bourdieu, 2002, p. 188, grifos no original).

No rastro das possibilidades de conciliação entre uma forma de conhecimento fenomenológico e outra objetivista, elaborada, sobretudo, por Bourdieu (2002) entre os teóricos da prática, manifesta-se no cenário antropológico da década de 1990 um clamor por estudos que tomassem como foco os "corpos-sujeitos nas suas relações com o mundo" (Ingold, 2000, p. 170). Para Csordas (2008), que analisa a proposta de Bourdieu sobre a teoria da ação (1996), em paralelo com a fenomenologia de Merleau-Ponty (2005), o fato da prática se estabelecer em oposição às estruturas sociais não é suficiente para superar a dualidade entre sujeito e objeto. Ao ligar a filosofia de Merleau-Ponty (2005) sobre o fenômeno da percepção e a teoria de Bourdieu (2002) sobre o habitus como resultado das práticas incorporadas, Csordas (2008) propõe que a corporeidade, mais do que um conceito antropológico, é uma perspectiva paradigmática para o estudo da cultura e do self. Assim, define-se o paradigma do embodiment. Para Csordas (2008), a corporeidade (embodiment) se inicia com o postulado metodológico de que o corpo não é um objeto a ser estudado em relação à cultura, mas deve ser considerado um sujeito da cultura ouum plano existencial para a cultura.

Seu argumento se completa na conjugação de um interesse empírico diferente, segundo o qual as estruturas sociais são incorporadas "na conjunção entre as condições objetivas de vida e a totalidade das aspirações e das práticas compatíveis com essas condições" (Csordas, 2008 , p. 111). Seu plano para delinear o paradigma do embodiment se vale, então, da teoria fenomenológica da percepção, no intuito de superar a dualidade entre sujeito e objeto, e da teoria da prática, para questionar a dualidade entre estrutura e prática. A exposição hermenêutica dessas duas orientações metodológicas resulta numa nova interpretação para a distinção sujeito-objeto, que limita a questão metodológica central ao paradigma do embodiment.
A força da proposta de Csordas (2008) reside na afirmação bastante simples de que se nós não percebemos nossos próprios corpos como objetos, também não podemos perceber outros corpos como objetos (Csordas, 2008). Se a fenomenologia de Merleau-Ponty (2005) explica que a comunicação se realiza na experiência perceptiva incorporada, então somos levados a experimentar a subjetividade do outro numa dimensão intersubjetiva. Assim, o corpo das outras pessoas pode se tornar um objeto para nós apenas secundariamente, como resultado da reflexão. "A experiência de ser um outro self”, diz Csordas (2008, p. 137), “é uma parte importante daquilo que distingue a nossa experiência do outro social", que "está, em um sentido radical, na negação do próprio self (not-self)". O que há de ser levado em conta é que os objetos culturais, dentre os quais está o self, são constituídos e objetificados não durante o processo de socialização infantil, mas no fluxo de toda a vida cultural do ser humano.

\section{Pensando sobre as práticas no ambiente}

O paradigma do embodiment questiona o caminho para se chegar às objetificações culturais e do sujeito (Csordas, 2008). Por meio das articulações entre o pensamento de Merleau-Ponty e o pensamento de Bourdieu, Csordas (2008) tenta mostrar que uma análise da percepção (o pré-objetivo) e da prática (o habitus) fundada no corpo permite investigar como os objetos culturais são constituídos ad continuum na indeterminação da vida cultural. A perspectiva do habitar, formulada por Ingold (2000), vem se somar a esse escopo paradigmático, ao propor que os interesses se voltem, justamente, para a realidade objetiva indeterminada e fenomenológica do viver-no-mundo. Para o autor (Ingold, 2000, p. 171), “a mente e suas propriedades não são dadas previamente à entrada do indivíduo no mundo social, mas, ao invés disso, são formadas na história do envolvimento de toda uma vida com os outros". É possível depreender que a percepção do social está fundamentada no envolvimento direto, mútuo e atento da pessoa com os outros no próprio contexto da experiência, anterior à representação.

O paradigma do embodiment trilha os caminhos abertos pela fenomenologia para advogar em favor da 
ideia de que o conhecimento do mundo é adquirido a partir da experiência direta, sempre mediatizada por estruturas sociais incorporadas que condicionam certas formas de percepção. Em concordância, a perspectiva do habitar se apega à preocupação de compreender as maneiras segundo as quais as pessoas percebem, agem, pensam, aprendem e cultivam suas memórias e, principalmente, como essas experiências estão condicionadas ao contexto de envolvimento prático com um mundo vivido.

Com a ajuda da vertente fenomenológica de Merleau-Ponty e o deslocamento do foco de análise de um ser abstrato que dá sentido ao mundo para outro que tome o ser-no-mundo (Velho, 2001), Ingold (2000) recorrerá à Psicologia, por via da vertente ecológica (Gibson, 1979), para delinear uma fenomenologia do habitar que subentende as práticas da vida em contexto. A ecologia, e com ela o holismo, que são referências-chave em Bateson (1999) e se aprofundam em Ingold (2000), com a influência de Merleau-Ponty, parecem propícios para dar sequência ao deslocamento da dualidade entre sujeito e objeto e, a partir disso, da série de oposições que inclui a clássica natureza versus cultura. Neste ponto, o distanciamento da representação abre espaço para o imenso terreno do processo primário, pré-reflexivo, destacado por Merleau-Ponty. "Terreno não do irracionalismo, mas das 'razões do coração', na expressão de Pascal retomada repetidamente por Bateson" (Velho, 2001, p. 137), onde a metáfora e o simbolismo não existem como figuras de linguagem mobilizadas para traduzir a experiência, mas sim no seu sentido mais forte, como modo de comunicação vital(Velho, 2001).

Para Ingold (2000, p. 34), uma aproximação adequada da ecologia toma como ponto de partida "a totalidade-organismo-no-seu-ambiente". Em outras palavras, o "organismo mais (plus) ambiente" denota uma totalidade indivisível, e uma ecologia da vida deve lidar com a dinâmica desse sistema totalidade, sem distinções entre a mente, a consciência, o organismo como um todo e o meio de seu envolvimento criativo com o mundo. Longe de revelar formas previamente especificadas, a vida é o processo da geração em curso, em que "cada ser vivo emerge, então, como uma incorporação (embodiment) particular e posicionada de seu potencial gerativo" (Ingold, 2000, p. 51). Nesse sentido, a experiência com o ambiente contribui com a formação da consciência do organismo-pessoa sobre ele mesmo, de suas atitudes e orientações em relação ao mundo. A experiência não pode ser tomada como o elemento mediador entre mente e natureza, uma vez que esses dois domínios não são separados (Bateson, 1999). Ao invés disso, ela deve ser entendida como intrínseca ao processo em andamento de estar vivo no mundo, do envolvimento total do organismo-pessoa com o ambiente.

Aliás, definir o que se entende por meio da noção de mundo é uma questão central para a perspectiva do habitar. Indubitavelmente, vivemos em um mundo que se desnuda aos nossos sentidos e com o qual interagimos de maneira prática nos múltiplos processos que constituem o viver. Isso não impede, contudo, que as divisões artificialmente construídas entre cultura e natureza façam com que o mundo seja pensado como um objeto de contemplação separado dos domínios da experiência vivida. A imagem do globo terrestre - o planeta Terra -, desenvolvida em campos de conhecimento tão diversos quanto a Biologia, a Geologia e a Astrofísica, apresenta o mundo como entidade metafísica, que evoca certas experiências transcendentais de percepção, como a ilusão de podermos "ver o mundo por fora", como um corpo celeste que gravita no espaço, ou "ver o mundo por dentro", como a superposição de camadas que se cobrem umas às outras a partir de um núcleo.

De maneira semelhante, os discursos articulados contemporaneamente no âmbito da Geopolítica e mesmo das Ciências Sociais empregam como jargão a "perspectiva local" e a "perspectiva global", estando a primeira contida na segunda e sendo, por consequência, uma parte da totalidade representada por ela. Se a concepção de uma "perspectiva global" reforça o distanciamento metafísico de um ser que está fora do mundo e que pode enxergá-lo plenamente, a concepção de uma "perspectiva local" reduziria a vida dos seres-no-mundo (ou seja, a vida das pessoas comuns) à incompletude. Segundo Ingold (2000), o mundo concebido como o globo, o planeta Terra em sua amplidão, consiste na materialidade pura e, ao mesmo tempo, impenetrável - porque apenas podemos ocupá-lo em sua superfície -, cujo sentido é uma abstração elaborada pela mente humana. Neste caso, conhecer o mundo não é o resultado de um engajamento perceptivo, mas de uma reconstrução cognitiva, como se 
"o mundo se tornasse uma tábula rasa para a inscrição da história humana” (Ingold, 2000, p. 214).

O mundo assim concebido é um objeto a ser transformado pela ação humana que lhe é exógena. Partindo de uma ontologia do destacamento (ontology of detachment), o pensamento ocidental concebe que a construção da ordem humana enseja a destruição da ordem natural, como se as práticas do viver humano no mundo fossem artificiais - resultado de construções culturais que se interpuseram à natureza. Uma ontologia do engajamento (ontology of engagement) explica os modos de compreensão do mundo de maneira não construtivista, baseando-se "no engajamento prático e perceptual com os componentes de um mundo que é habitado e vivido (inhabited and dwelt-in), ao invés da observação desinteressada e destacada (detached) de um mundo que é meramente ocupado" (Ingold, 2000, p. 216). A forma de compreensão fenomenológica assim enunciada situa a pessoa no mundo, mais precisamente no "centro de um universo ordenado de relações significativas" (Ingold, 2000).

Nessa medida, como anuncia Merleau-Ponty (2005), o mundo nunca pode ser separado da pessoa que o percebe. Isso porque: "toda percepção é uma comunicação ou uma comunhão, a retomada ou o acabamento, por nós, de uma intenção alheia ou, inversamente, a realização, no exterior, de nossas potências perceptivas como um acasalamento de nosso corpo com as coisas" (Merleau-Ponty, 2005, p. 429). O acasalamento da pessoa com o mundo origina ambos, simultaneamente, pois ainda que o mundo esteja lá antes de tudo, o devir da pessoa exerce um impacto natural sobre ele. O mundo, então, pode ser definido como o meio inextricável, no qual o engajamento das pessoas com o ambiente origina e é originário das práticas do viver. Meio no qual as pessoas estão imersas e existem nos termos de uma simbiose, de uma inter-relação tão íntima, que se torna essencial à vida, de um entrelaçamento no qual pessoa e mundo estão de tal modo interligados que uma parte não pode ser descrita sem menção à outra, mesmo que o conjunto formado por elas seja divisível.

A perspectiva do habitar proposta por Ingold (2000) é inspirada também pela fenomenologia de Heidegger, principalmente pelo trabalho "Building Dwelling Thinking” (Heidegger, 1971), no qual o filósofo questio- na o que significa construir e habitar e qual é a relação entre essas duas práticas. Segundo Ingold (2000, p. 185), Heidegger principia por apresentar aquilo que pode ser chamado de "visão hegemônica, consagrada pelo discurso da modernidade ocidental", qual seja, conceber "o construir e o habitar como atividades separadas, mas complementares, relacionadas como meio e finalidade". Habitar, nesse sentido, refere-se apenas a ocupar uma casa ou um espaço de habitação, enquanto a construção é o lugar que acolhe certas atividades da vida.

Para a visão hegemônica, o habitar fica circunscrito à construção, ao passo que, conforme o pensamento de Heidegger, esta posição parece reversa. Sua preocupação é recuperar essa última perspectiva, para que "possamos voltar a compreender como as atividades envolvidas no construir - cultivar, edificar - pertencem ao nosso habitar do mundo, à forma como somos" (Ingold, 2000, p. 186). Isso significa que as maneiras por meio das quais as pessoas constroem ou elaboram o ambiente surgem no curso do seu envolvimento em atividades práticas, como o contexto relacional do seu engajamento prático com o mundo. Construções, bem como qualquer outra forma de modulação e organização do ambiente e das atividades que nele são desempenhadas, não podem ser entendidas como simples processos de transcrição de um design preexistente até o resultado final, a partir de matérias-primas brutas - sendo o espaço a principal delas. Certamente, as pessoas têm capacidade de projetar o meio onde vivem e os objetos que o preenchem, mas essa capacidade visionária é, em si mesma, uma atividade desenvolvida no ambiente. Apenas porque as pessoas habitam o mundo é que elas podem pensar, sentir e agir da maneira como fazem. E o fazer do mundo por meio da prática da construção é resultado do fazer das pessoas por meio da prática do habitar.

Construir é um processo em contínuo andamento, tão duradouro quanto possa ser o habitar da pessoa e de um grupo no ambiente. A construção "não começa aqui, com um plano pré-formulado, e termina lá, como um artefato acabado", antes o contrário. As pessoas participam ativamente da construção do ambiente onde vivem, ainda que o plano ou projeto dessa construção não tenha sido idealizado diretamente por elas. Isso porque elas constroem o ambiente de dentro para fora, por meio de práticas que impõem certa organização ao ambiente. 
Embora o ambiente jamais chegue a apresentar uma forma acabada, por outro lado, ele se constitui enquanto registro duradouro - uma marca ou testemunho - das vidas e das práticas das pessoas que o habitaram e que deixaram ali algo de si mesmas. Segundo Ingold (2000, p. 189), "para os antropólogos, adotar uma perspectiva deste tipo significa dar suporte à ideia de que o conhecimento nasce da experiência íntima, privilegiando os entendimentos que as pessoas derivam de seu envolvimento vivencial e cotidiano com o mundo". Significa também elaborar uma espécie de "crônica da vida e do habitar" (Ingold, 2000, p. 189), posto que o ambiente que abriga as práticas carrega consigo uma parte da vida dos habitantes/praticantes que participaram da sua construção. Assim, tem-se que as práticas no ambiente e os atos de percepção que derivam delas e as condicionam implicam a recordação dessa crônica - mas recordar não se coloca, nesse sentido, como uma questão de relembrar, ou evocar imagens internas, armazenadas na mente. Recordar é recuperar aquilo que sabemos de cor; é mergulhar no estado de engajamento perceptual com um ambiente impregnado de resquícios de práticas passadas.

Ingold (2000) propõe que "dizer 'eu habito, você habita' é idêntico a dizer 'eu sou, você é"” (p. 185), porque "corpo e ambiente são termos complementares: um implica o outro, alternadamente, como figura e fundo" (p. 193). O autor propõe, ainda, que "no habitar o mundo, nós não agimos sobre ele, ou fazemos algo em relação a ele; ao invés disso, nós nos movemos com ele" (Ingold, 2000, p. 200). Tudo isso exprime a ideia de que o engajamento ou o entrelaçamento com o mundo existe como inter-atividade das pessoas sobre o ambiente e do ambiente sobre as pessoas. Para que o ambiente seja habitado, é preciso que abrigue as práticas de agentes, que se ofereça como suporte para a vida tanto quanto condicione as maneiras possíveis de viver, e carregue em si a temporalidade intrínseca a essa dinâmica.

Assim, "a vida das pessoas e a história de suas relações podem ser traçadas nas texturas do ambiente" (Ingold, 2000, p. 150). Em síntese, tomar o ambiente como contexto de práticas pretende exprimir a ideia da contextura; da ligação da vida das pessoas - no passado, no presente e nas suas projeções futuras - formando um arranjo, uma estrutura, um sistema. Esse contexto, ou contextura, está certamente relacionado a aspectos da interação ecológica dos organismos-pessoa com o ambiente, como também da interação econômica das práticas que asseguram a manutenção da vida e da interação social que liga os indivíduos com motivações comuns para o desempenho das práticas.

Para além da dicotomia natureza/cultura, a ideia de contexto, reduzida a partir da perspectiva do habitar, implica que a fonte do conhecimento característico da cultura repousa nas pessoas tanto quanto no ambiente. Desempenhar uma prática é recordar as ações desempenhadas por praticantes anteriores, ao mesmo tempo em que se elaboram novas maneiras de agir em face das mudanças no contexto. O que importa, conforme Ingold (2000, p. 147), é que a prática se perpetue e "não que deva se reproduzir em réplicas precisas das performances passadas". Essa dinâmica demanda uma boa dose de criatividade, afinal "uma prática bem recordada é aquela que se apresenta como uma resposta flexível para cada condição variável do ambiente". Por conseguinte, a perspectiva do habitar não opõe as circunstâncias de continuidade e mudança, e ainda expõe o fato de que a mudança está, na verdade, intrínseca à continuidade. A mudança é o que se observa quando tomamos alguns momentos diferentes de uma mesma prática separados no tempo, ao passo que a continuidade é o que se tem ao perfilar ou sobrepor todos os momentos dessa prática, fazendo com que o aglomerado de todos eles forme um corpus coeso. O desenvolvimento de um organismo, por exemplo, é um processo contínuo, mas se observarmos algumas etapas do seu crescimento em separado, notaremos a mudança. De maneira análoga, o desenvolvimento de uma prática contém o aspecto da mudança das pessoas no seu envolvimento umas com as outras e com o ambiente sem deixar, porém, de ser contínuo (Ingold, 2000).

\section{Considerações finais}

Neste ensaio, discutimos o que é a perspectiva do habitar, alinhada com o paradigma do embodiment, para aprofundar o entendimento de mundo-da-vida. Nossos esforços foram dirigidos a contribuir para as teorias da prática no âmbito dos EOs, recuperando seu potencial crítico com a introdução de entendimentos que pressu- 
põem reexaminar e reconceituar a prática e o substrato material e cultural onde se desenvolve. Nossa proposta buscou fornecer uma forma de entendimento que descreva as práticas a partir da ideia do entrelaçamento no mundo da vida, como processo corporal e incorporado situado no ambiente. Ambiente que, por sua vez, foi definido não apenas enquanto o lugar onde as práticas acontecem, mas como espaço que é construído por elas e que, mutuamente, as constrói. O processo de habitar - inter-relação da pessoa com o contexto, definido em sua complexidade - é o próprio entrelaçamento com o mundo da vida.

As construções teóricas que elaboramos neste artigo vêm se aliar ao movimento cuja ênfase nas pesquisas tem recaído sobre a temática das práticas nos EOs (Schatzki, 2001). A proposição consiste na compreensão das práticas como relação de conhecimento corporal e incorporada, a partir de entendimentos que se opõem ao cognitivismo. Além disso, o esforço empreendido neste artigo, no sentido de esclarecer a perspectiva do habitar, vem se somar ao entendimento das práticas situadas no mundo da vida para dar conta da complexidade e da profundidade das relações mediadas por elas. Sendo assim, nossa contribuição se dirige a preencher duas lacunas identificadas nos estudos sobre as práticas nos EOs: (1) o esforço de resgatar o potencial crítico das práticas em relação aos conceitos positivistas e racionalistas impostos aos estudos organizacionais, conforme apontam Geiger (2009) e Gherardi (2009a); e (2) a necessidade de promover uma articulação mais clara do entrelaçamento com o mundo da vida que, segundo Sandberg \& Dall'Alba (2009), é crucial para a análise da prática.

Direcionando nossa análise para uma perspectiva mais concreta e aplicada das discussões teóricas desenvolvidas ao longo do texto, importa esclarecer que reflexões sobre o entrelaçamento das pessoas e das organizações com o mundo-da-vida têm por objetivo corroborar uma ontologia do engajamento, que se opõe a uma ontologia do destacamento (Ingold, 2000) dos seres humanos e da cultura em relação à natureza. A relação predatória que os seres humanos modernos, participantes de culturas ocidentais ou ocidentalizadas, mantém com o meio ambiente comprova o sentido e a prática desse destacamento. Nos últimos cem anos, até mesmo os mais céticos puderam perceber que as atividades orga- nizacionais têm causado danos devastadores para o meio ambiente natural. Isso porque "o capitalismo não se desenvolve sobre a natureza, ele emerge através de relações confusas e contingentes de humanos com o restante da natureza" (Moore, 2011, p. 115). A perspectiva antropocêntrica que orienta os EOs pouco tem se esforçado em problematizar as organizações como abstrações que surgem a partir da relação ecológica dos seres humanos com o ambiente (Ezzamel \& Willmot, 2014). Sendo assim, no plano da teoria, a orientação hegemônica no campo dos EOs falha em contribuir com entendimentos alternativos sobre o conceito de organização que sejam capazes de abrigar outras formas de compreensão das relações econômicas e ecológicas.

No plano do discurso e das práticas gerenciais, o ambientalismo emergiu como uma corrente influente, com a proposta de lidar com os desafios da preservação ambiental (Shrivastava, 1994). Desde então, as reflexões que se articularam sob esse emblema não têm dado demonstrações de capacidade para lidar com a relação entre capital e natureza. Constata-se que, a despeito do crescimento do interesse público sobre a preservação ambiental, um discurso que se transmuta da ideia de desenvolvimento sustentável à economia verde tem sido articulado enquanto estratégia que permite "ao capital cooptar conceitos inicialmente radicais, tais como sustentabilidade, de modo a inclui-los em sua lógica de acumulação" (Misoczky \& Böhm, 2012, p. 546). O que se observa no âmbito das práticas gerenciais que se propõem a lidar com a questão ambiental é que o pensamento ecológico conservacionista tem sido cooptado em nome das velhas lógicas que entendem a natureza como recurso. Os EOs, como um campo capaz de influenciar as práticas gerenciais, não foi capaz até agora de empenhar-se seriamente na crítica dos discursos ambientais correntes.

$\mathrm{Na}$ década de 1990, no alvorecer das discussões ambientais, Shrivastava (1994) já chamava atenção para o fato de que as teorias organizacionais não poderiam tratar adequadamente as preocupações ambientais por causa de suas ideias limitadas de "ambiente organizacional". O presente artigo buscou contribuir para superar essas limitações esclarecendo e aprofundando uma proposta anterior (Sandberg \& Dall'Alba, 2009) e compactuando com ela da necessidade de ampliar a compreensão das 
organizações e das práticas organizacionais a partir da perspectiva do mundo-da-vida. Para que a corrente teórica evidenciada nesse estudo contribua efetivamente para uma nova abordagem sobre as práticas, outros entendimentos sobre o mundo-da-vida permanecem sendo necessários, assim como são necessárias investigações empíricas que façam avançar o quadro conceitual e desenvolvam métodos de investigação e formas de apresentação da pesquisa coerentes com a complexidade das práticas organizacionais.

Inicialmente, pode-se pensar que o alcance empírico da perspectiva do habitar se aplicaria a grupos ou comunidades regidas pela longa duração, entendidas como tradicionais por manterem relação diferente com o mundo-da-vida quando comparadas aos grupos plenamente inseridos no capitalismo e na cultura ocidental. A antropologia ecológica praticada por Ingold (2000) tem essa orientação fortemente estabelecida e a partir de seus relatos etnográficos podemos entender o que é o mundo-da-vida e a relação de engajamento prático com ele. Todavia, no contexto do capitalismo contemporâneo, o entendimento de relações diferenciadas com o mundo-

\section{Referências}

Bateson, G. Steps to an ecology of mind. Chicago: University of Chicago Press, 1999.

Bourdieu, P. Razões práticas: sobre a teoria da ação. Campinas: Papirus, 1996.

Bourdieu, P.. Esboço de uma teoria da prática: precedido de três estudos de etnologia cabila. Oieiras: Celta, 2002.

Certeau, M. A invenção do cotidiano. Petrópolis: Vozes, 2002.

Cohen, M. Reading Dewey: reflections on the study of routines. Organization Studies, 28(5), 773-786, 2007. doi: 10.1177/0170840606077620.

Corradi, G.; Gherardi, S.; Verzelloni, L. Thought the practice lens: where is the bandwagon of the practice-based studies heading? Management Learning, 41(3), 265-283, 2010. doi: $10.1177 / 1350507609356938$.

Csordas, T.A corporeidade como um paradigma para a antropologia. In: Csordas, T. Corpo, significado, cura. Porto Alegre: UFRGS, 2008. p. 110-146. -da-vida é também possível e passível de ser observado. Como sugestão de desdobramentos futuros das reflexões iniciadas aqui, podemos propor, por exemplo, análises, a partir da epistemologia do habitar, de grandes projetos de impacto socioambiental (exploração de petróleo, empreendimentos energéticos de barragens, exploração de minérios, etc.) em que populações locais são alvo de experiências de impacto e de rupturas quase definitivas. Nessas análises, convém articular a abordagem fenomenológica com uma perspectiva crítica que exponha a prevalência do entendimento do ambiente como recurso e do imperativo do desenvolvimento como mola mestra para a investida do mercado sobre a natureza, sobre culturas e sobre modos de vida que compartilham de ontologias diferentes da ecologia-mundo capitalista (Moore, 2011), ainda que não sejam exteriores ao capitalismo. Assim, os lugares onde as relações centro-periferia globais e as diferenças que encerram no tocante ao conceito de desenvolvimento tornam-se, respectivamente, campos e objetos empíricos para estudos baseados na perspectiva do habitar.

Ezzamel, M.;Willmott, H. Registering 'the ethical' in organization theory formation: towards the disclosure of an 'invisible force'. Organization Studies, 35(7), 1013-1039, 2014. doi: $0.1177 / 0170840614525324$.

Feldman, M. Organizational routines as a source of continuous change. Organization Science, 11(6), 611-629, 2000. doi: 10.1287/orsc.11.6.611.12529.

Feldman, M.; Pentland, B. T. Re-conceptualizing organizational routines as a source of flexibility and change. Administrative Science Quarterly, 48(1), 94-118, 2003. doi: 10.2307/3556620.

Foucault, M. História da sexualidade: a vontade de saber. São Paulo: Graal, 2009.

Geiger, D. Revisiting the Concept of Practice: Toward an Argumentative Understanding of Practicing. Management Learning, 40(2), 129-144, 2009. doi: 10.1177/1350507608101228.

Gibson, J. The Ecological Approach to Visual Perception. London: Lawrence Erlbaum, 1979. 
Gherardi, S. Practice? It's a matter of taste. Management Learning, 40(5), 535-550, 2009a. doi: 10.1177/1350507609340812.

Gherardi, S. Introduction: the critical power of the practice lens. Management Learning, 40(2), 115-128, 2009b. doi: $10.1177 / 1350507608101225$.

Giddens, A. The constitution of society. Cambridge: Polity, 1984.

Hancock, P. Embodied generosity and ethics of organization. Organization Studies, 29(10), 1357-1379, 2008. doi: $10.1177 / 0170840608093545$.

Heidegger. Poetry, language, thought. New York: Harper \& Row, 1971.

Ingold, T. Perceptions of environment: essays on livelihood, dwelling and skill. London and New York: Routledge, 2000.

Knorr-Cetina, K. Sociality with objects: social relations in post-social knowledge societies. Theory, Culture and Society, 14(4), 1-30, 1997. doi: 10.1177/026327697014004001.

Latour, B. Jamais fomos modernos. Bauru: EDUSC, 2007.

Merleau-Ponty, M. Fenomenologia da percepção. São Paulo: Martins Fontes, 2005.

Misoczky, M. C.; Böhm, S. Do desenvolvimento sustentável à economia verde: a constante e acelerada investida do capital sobre a natureza. Cadernos EBAPE.BR, 10(3), 546-568, 2012. doi: 10.1590/S1679-39512012000300006.

Moore, J. W. Ecology, capital and the natures of our times: a theory of crisis in the capitalist world-ecology. Journal of World-System Analysis, 17(1), 107-146, 2011. Disponível em: $<$ http://www.cemus.uu.se/dokument/CCL_2011/Ecology\%20 Capital\%20and\%20Nature.pdf $>$.
Ortner, S. Theory in anthropology since the sixties. Comparative Studies in Society and History, 26(1), 126-166, 1984. Disponível em: <http://www.jstor.org/stable/178524>.

Reckwitz, A. The status of 'material' in theories of culture: from 'social structures' to 'artifacts'. Journal of the Theory of Social Behaviour, 32(2), 195-217, 2001. doi: 10.1111/1468-5914.00183.

Sahlins, M. Cultura e razão prática. Rio de Janeiro: Jorge Zahar, 2003.

Sandberg, J.; Dall'Alba, G. Returning to practice anew: a lifeworld perspective. Organization Studies, 30(12), 1349-1368, 2009. doi: 10.1177/0170840609349872.

Schatzki, T. Practices and actions: a Wittgensteinian critique of Bourdieu and Giddens. Philosophy of the Social Sciences, 27(283), 283-308, 1997. doi: 10.1177/004839319702700301.

Schatzki, T. Introduction. Practice Theory. In: Schatzki, T.; Knorr-Cetina, K.; Von Savigny, E. (Eds.).The Practice Turn in Contemporary Theory. London and New York: Routledge, 2001. p. 1-14.

Schatzki, T. Organizations as they happen. Organization Studies, 27(12), 1863-1873, 2006. doi: 10.1177/0170840606071942.

Shrivastava, P. Castrated environment: greening organizational studies. Organization Studies, 15(5), 705-726, 1994. doi: $10.1177 / 017084069401500504$.

Strati, A. Sensible knowledge and practice based learning. Management Learning, 38(1), 61-77, 2007. doi: 10.1177/ 1350507607073023.

Velho, O. De Bateson a Ingold: um passo na constituição de um paradigma ecológico. Maná, 7(2), out. 2001. Disponível em: <http://www.scielo.br/pdf/mana/v7n2/a05v07n2.pdf>.

Weber, M. Economia e sociedade. Brasília: UnB, 2004. v. 1. 